\title{
A fast and simple method to estimate relative, hyphal tensile-strength of filamentous fungi used to assess the effect of autophagy
}

Quintanilla, Daniela ; Chelius, Cynthia; lambamrung, Sirasa; Nelson, Sidney; Thomas, Donnel; Gernaey, Krist V.; Marten, Mark R

Published in:

Biotechnology and Bioengineering

Link to article, DOI:

10.1002/bit.26490

Publication date:

2018

Document Version

Peer reviewed version

Link back to DTU Orbit

Citation (APA):

Quintanilla, D., Chelius, C., lambamrung, S., Nelson, S., Thomas, D., Gernaey, K. V., \& Marten, M. R. (2018). A fast and simple method to estimate relative, hyphal tensile-strength of filamentous fungi used to assess the effect of autophagy. Biotechnology and Bioengineering, 115(3), 597-605. https://doi.org/10.1002/bit.26490

\section{General rights}

Copyright and moral rights for the publications made accessible in the public portal are retained by the authors and/or other copyright owners and it is a condition of accessing publications that users recognise and abide by the legal requirements associated with these rights.

- Users may download and print one copy of any publication from the public portal for the purpose of private study or research.

- You may not further distribute the material or use it for any profit-making activity or commercial gain

- You may freely distribute the URL identifying the publication in the public portal 
Bioprocess Engineering and Supporting Technologies

Biotechnology and Bioengineering DOI 10.1002/bit.26490

A fast and simple method to estimate relative, hyphal tensile-strength of filamentous fungi used to assess the effect of autophagy

Daniela Quintanilla ${ }^{1}$, Cynthia Chelius², Sirasa Iambamrung ${ }^{2}$, Sidney Nelson², Donnel Thomas $^{2}$, Krist V. Gernaey ${ }^{1}$, Mark R. Marten²

${ }^{1}$ Department of Chemical and Biochemical Engineering, Technical University of Denmark, Kgs. Lyngby, Denmark

${ }^{2}$ Department of Chemical and Biochemical Engineering, University of Maryland Baltimore County (UMBC), 1000 Hilltop Circle, Baltimore, MD 21250

Corresponding author: Mark Marten Tel. (410) 455-3439. Fax: (410) 455-1049.; e-mail: marten@umbc.edu

†This article has been accepted for publication and undergone full peer review but has not been through the copyediting, typesetting, pagination and proofreading process, which may lead to differences between this version and the Version of Record. Please cite this article as doi: [10.1002/bit.26490]

Additional Supporting Information may be found in the online version of this article.

This article is protected by copyright. All rights reserved

Received October 9, 2017; Accepted November 6, 2017 


\section{ABSTRACT}

Fungal hyphal strength is an important phenotype which can have a profound impact on bioprocess behavior. Until now, there is not an efficient method which allows its characterization. Currently available methods are very time consuming; thus, compromising their applicability in strain selection and process development. To overcome this issue, a method for fast and easy, statistically-verified quantification of relative hyphal tensile strength was developed. It involves off-line fragmentation in a high shear mixer followed by quantification of fragment size using laser diffraction. Particle size distribution (PSD) is determined, with analysis time on the order of minutes. Plots of PSD $90^{\text {th }}$ percentile versus time allow estimation of the specific fragmentation rate. This novel method is demonstrated by estimating relative hyphal strength during growth in control conditions and rapamycininduced autophagy for Aspergillus nidulans (paternal strain) and a mutant strain ( $\triangle$ Anatg8) lacking an essential autophagy gene. Both strains were grown in shake flasks, and relative hyphal tensile strength was compared. The mutant strain grown in control conditions appears to be weaker than the paternal strain, suggesting that Anatg8 may play a role in other processes involving cell wall biosynthesis. Furthermore, rapamycin-induced autophagy resulted in apparently weaker cells even for the mutant strain. These findings confirm the utility of the developed method in strain selection and process development. This article is protected by copyright. All rights reserved

\section{KEY WORDS}

Hyphal strength, fragmentation, filamentous fungi, autophagy, fermentation 


\section{INTRODUCTION}

Due to their exceptional capacity to express and secrete significant quantities of both native and recombinant protein, filamentous fungi have become indispensable for the production of industrial enzymes (Meyer, 2008). Industrial enzyme production is typically carried out in large-scale aerobic fermentations. However, as fungal biomass increases, broth viscosity often increases significantly, resulting in oxygen mass-transfer limitations (Metz et al., 1979; Olsvik and Kristiansen, 1994). To cope with these limitations, a simple strategy is to increase agitation intensity. Increased agitation also impacts fungal morphology, typically resulting in a reduction in the mean size of fungal elements (both freely-dispersed form and clumps; (Nienow, 2009). These smaller fungal elements can have an indirect positive impact on productivity, as smaller fragments lead to reduced viscosity allowing increased oxygen masstransfer (Amanullah et al., 2002; Johansen et al., 1998). Thus, in a DO-controlled feeding of a fungal fermentation, productivity will be enhanced with smaller fragments (Bhargava et al., 2003).

During a submerged fermentation, the average size of fungal elements is the result of two opposing phenomena. Fragmentation occurs due to shear forces, imposed by hydrodynamic conditions in the tank, while resistance to fragmentation is dependent on hyphal tensile strength. van Suijdam and Metz (1981) suggested, based on Kolmogorov's theory of isotropic turbulence, that when the local shearing forces are larger than hyphal tensile strength, fragmentation occurs. The size of the hyphae at which equilibrium is achieved is called the equilibrium effective length (van Suijdam and Metz, 1981). "Hyphae longer than this maximum value will fragment and hyphae shorter than this maximum value will not be further reduced in size” (Nielsen and Krabben, 1995). This implies there is a limit on how agitation can be manipulated to control broth rheology. Another significant limitation in using increased agitation to control broth rheology is the significant capital investment 
required to purchase larger motors and the increased power requirements required to operate them.

These ideas suggest that when attempting to control fungal broth rheology, an alternative to increased agitation is manipulation of hyphal tensile strength. While a number of authors have assumed fungal tensile strength to be constant (Johansen et al., 1998; Nielsen and Krabben, 1995; van Suijdam and Metz, 1981), more recent studies show this is not the case, and that tensile strength of fungal hyphae changes during growth (Li et al., 2002a,b). This raises clear questions regarding the dependence of hyphal strength on culture conditions and/or genetic variables. And, even more importantly, the question should be raised also whether we can actively manipulate these in order to favor fragmentation and thus positively impact fermentation productivity.

These ideas imply hyphal strength is a particularly important phenotype in fungal bioprocesses, and thus it would be ideal to have an easy, fast and reproducible method that allows its characterization. Different approaches have been developed to measure hyphal strength based on pressure or mechanical forces (Money and Hill, 1997; Stocks and Thomas, 2001). However, these methods rely on sophisticated equipment or measuring techniques, and generally measure the strength of a single cell, not the population. A population-based method has been developed ( $\mathrm{Li}$ et al., 2002b), which is based on off-line fragmentation to quantify the relative hyphal tensile strength. Fungal broth is removed from a growing culture, and subjected to high shear in a mixer over a very short period of time; samples are removed every few seconds and the change of average size for the fungal elements is quantified by image analysis ( Li et al., 2002b). While off-line fragmentation in a high shear mixer is fast and relatively simple, the image analysis required is extremely time consuming, and requires several days to be performed. Therefore, there is need for a method which allows rapid 
characterization of hyphal strength phenotype to be used in strain selection and process development.

In this work, the technique originally reported by Li et al. (2002b) was further developed to create an easy and rapid method that allows reproducible quantification of relative hyphal strength. The first part of the assay, i.e., off-line fragmentation, remains unchanged. Here though, instead of using image analysis, average size of fragmented samples is analyzed using laser diffraction. Changes in hyphal morphology (i.e., fungal element size) are quantified by measuring particle size distribution (PSD). Plots of the $90^{\text {th }}$ percentile of the PSD versus time in the high shear mixer allow estimation of the instantaneous specific fragmentation rate, $k_{\mathrm{frag}}$, which is inversely proportional to hyphal tensile strength.

To test reproducibility and applicability of the new method, we used shake flask cultures, grown under autophagy induced conditions (i.e., added rapamycin), to determine the impact on specific fragmentation rate. It was previously suggested that one of the effects of rapamycin-induced autophagy is the degradation of cell wall components, even in the presence of available exogenous carbon (Kim et al., 2011). Thus, we hypothesized a weaker hyphal cell wall should be observed during induced autophagy in comparison to control conditions. Additionally, the role of A. nidulans Anatg8 was examined using an Anatg8 gene deletion mutant. Anatg8 plays a key role in the autophagy pathway, and Anatg8 deletion mutants are autophagy deficient (Pollack, et al., 2009; Zustiak et al., 2008). The hyphal cell wall strength was tested both under control and rapamycin-induced autophagy conditions and compared to the isogenic parental strain (ie., Anatg8+). This further allowed testing the applicability of the method for strain selection by measuring the hyphal strength phenotyperesponse on genetic variations. Furthermore, since we are aware that fragmentation rate measured in the fashion reported in this paper is a function of mixer geometry and speed, we propose a strategy to enable inter-laboratory comparisons. 


\section{MATERIALS AND METHODS}

Strains and growth condition.

Wild type A. nidulans (FGSC A4) was used for the method development experiments. Spores were propagated from freeze-dried ampoules onto MAG plates, following incubation for 3 days at $28^{\circ} \mathrm{C}$. The MAG plates were made with $10 \mathrm{~g} / \mathrm{L}$ glucose, $20 \mathrm{~g} / \mathrm{L}$ malt extract, $15 \mathrm{~g} / \mathrm{L}$ agar, $2 \mathrm{~g} / \mathrm{L}$ peptone, $1 \mathrm{ml} / \mathrm{L}$ vitamin mix solution and $1 \mathrm{ml} / \mathrm{L}$ trace elements solution. The trace element solution was made of: $22 \mathrm{~g} / \mathrm{L} \mathrm{ZnSO}_{4} \cdot 7 \mathrm{H}_{2} \mathrm{O}, 11 \mathrm{~g} / \mathrm{L} \mathrm{H}_{3} \mathrm{BO}_{3}, 5 \mathrm{~g} / \mathrm{L} \mathrm{MnCl}_{2} \cdot 4 \mathrm{H}_{2} \mathrm{O}$, $5 \mathrm{~g} / \mathrm{L} \mathrm{FeSO}_{4} \cdot 7 \mathrm{H}_{2} \mathrm{O}, 1.7 \mathrm{~g} / \mathrm{L} \mathrm{CoCl}_{2} \cdot 6 \mathrm{H}_{2} \mathrm{O}, 1.6 \mathrm{~g} / \mathrm{L} \mathrm{CuSO}_{4} \cdot 5 \mathrm{H}_{2} \mathrm{O}, 1.5 \mathrm{~g} / \mathrm{L} \mathrm{Na}_{2} \mathrm{MoO}_{4} \cdot 2 \mathrm{H}_{2} \mathrm{O}$ and 50 g/L EDTA (Na4). The vitamin solution contained: 100 mg/L biotin, 100 mg/L pyridoxine, $100 \mathrm{mg} / \mathrm{L}$ thiamine, $100 \mathrm{mg} / \mathrm{L}$ riboflavin, $100 \mathrm{mg} / \mathrm{L}$ p-aminobenzoic acid, and $100 \mathrm{mg} / \mathrm{L}$ nicotinic acid. The spores were harvested with deionized water. Approximately $10^{7}$ spores were used to inoculate a $250 \mathrm{~mL}$ shake flask containing $50 \mathrm{ml}$ media. The shake flask media consisted of: $10 \mathrm{~g} / \mathrm{L}$ glucose, $20 \mathrm{~g} / \mathrm{L}$ malt extract, $2 \mathrm{~g} / \mathrm{L}$ peptone, $1 \mathrm{ml} / \mathrm{L}$ trace metal solution and $1 \mathrm{ml} / \mathrm{L}$ vitamin mix solution. The $\mathrm{pH}$ of the media was adjusted to $3.3 \pm 0.2$ with the addition of 1M HCl to ensure dispersed growth (Carlsen et al., 1996). After inoculation, the shake flasks were placed in an orbital shaker at $250 \mathrm{rpm}$ and $28^{\circ} \mathrm{C}$. The $12 \mathrm{~h}$ vegetative growth from this shake flask was used to inoculate a $2.8 \mathrm{~L}$ baffled Fernbach flask containing 1.2 $\mathrm{L}$ of the same media. The initial $\mathrm{pH}$ of the media in this shake flask was not adjusted, but did not vary significantly ( $\mathrm{pH} 6 \pm 0.2$ ). All flasks were incubated at $28{ }^{\circ} \mathrm{C}$ on an oscillating shaker at $250 \mathrm{rpm}$.

The applicability of the method was tested by measuring the specific fragmentation rate on a strain lacking a particular autophagy gene ( $\triangle \mathrm{atg} 8)$ and its paternal strain (TNO2A3) obtained from Dr. Steven D. Harris (Department of Plant Pathology and Center for Plant Science Innovation, University of Nebraska, NE, USA). For the control conditions (no autophagy), 
the strains were grown in the same media as for A. nidulans A4 but the media was enriched with uracil (1.2 g/L) and uridine (1.3 g/L), in addition to the MAG plates. Autophagy was induced in the exponential phase by adding $1 \mathrm{ml}$ of a concentrated rapamycin solution (20 $\mathrm{g} / \mathrm{L}$ ) to obtain a rapamycin concentration in the shake flasks of approx. $20 \mathrm{mg} / \mathrm{L}$, as in (Kim et al., 2011). Rapamycin addition occurred at $10 \mathrm{~h}$ for the TNO2A3 strain and at $13 \mathrm{~h}$ for the $\Delta$ atg8 strain. Samples were taken at different time intervals and dry cell weight measurements were performed along with $k_{\text {frag }}$ measurements. The amount of withdrawn sample depended on the expected biomass concentration, since it is required to have a minimal biomass concentration in order to achieve a stable reading in the particle size determination, as further described.

\section{Modifications to the fragmentation test of fungal hyphae}

In this work, the relative hyphal tensile strength was also estimated by measuring the relative fragmentation rate using a high-shear mixer (Black+Decker, BL2010BPA). The procedure was very similar as the one described by $\mathrm{Li}$ et al. 2002b and it is illustrated in Figure 1 . When the biomass concentration in the shake flasks was above $2 \mathrm{~g} / \mathrm{L}$, the samples were diluted $2 \mathrm{x}$. $200 \mathrm{ml}$ of properly diluted sample was placed in the high-shear mixer and the slowest speed was chosen. After short time intervals, approx. $1 \mathrm{ml}$ samples were taken from the mixer with a cut pipette tip (to prevent size exclusion) and placed in Eppendorf tubes. The times for sample removal from the high shear mixer were: 0s, 5s, 15s, 25s, 35s, 45 s and 55 s. The particle size distribution of these samples was measured using laser diffraction. The Mastersizer 3000 with a Hydro SM manual small sample dispersion unit (Malvern Instruments Ltd. Worcestershire, UK) was used. The $1 \mathrm{ml}$ sample from the high shear mixer was dispersed in tap water with a refractive index of 1.33. Using tap water ensured that no bubbles seated on the measurement area of the optical bench. The stirring was set to 1,800 rpm. A laser saturation of at least $1 \%$ was required in order to have a stable reading. Two or 
three successive measurements were performed for each sample, and a volume-weighted particle size distribution was calculated automatically in the Mastersizer 3000 software. The $90^{\text {th }}$ percentile of the particle size distribution, S90, was used as the parameter to characterize the morphological changes. Samples with biomass concentration less than $1 \mathrm{~g} / \mathrm{kg}$ were analyzed right away, while samples with a higher biomass concentration were fixed with $1 \mathrm{ml}$ fixative solution: 3.5\% formaldehyde, $50 \mathrm{mM}$ phosphate buffer ( $\mathrm{pH} 7.0$ ), 0.2\% Triton X-100, (Harris et al.1994).

\section{RESULTS AND DISCUSSION}

Relative hyphal tensile strength was determined with an approach similar to a method developed by Li et al. (2002b). The difference in the method proposed here is in how average particle size is characterized after samples have been fragmented in a high shear mixer. In the original method of Li et al., (2002b) image analysis was used. Here, we use laser diffraction to characterize morphological changes. Using laser diffraction for these type of measurements has been shown to be an easy and fast method to characterize fungal morphology (Petersen et al., 2008; Rønnest et al., 2012). Experience has shown that the relative fragmentation rate determination for one sample using image analysis for morphology characterization typically takes on the order of 20 hours. Thus a faster, more efficient, method would facilitate using this approach to evaluate phenotype for strain selection and process development procedures.

\section{Method Development}

Broth samples were removed from a shake flask of A. nidulans (strain A4) at 15 and $52 \mathrm{~h}$ and the specific fragmentation rate, $k_{\text {frag}}$, for each time point was estimated in triplicates. To do this, broth samples were subjected to high-shear mixing. During mixing, at short time 
intervals, small volumes were removed from the mixer so the particle size distribution (PSD) could be assessed via laser diffraction (Figure 2). It can be seen clearly that the laser diffraction method accounts for the changes in size due to the high shear forces in the mixer. The particle size distribution shifts to the left during high-shear mixer operation, as an indication of particle size reduction in both figures. Based on operational principals of the measurement equipment, reported data are proportional to the diameter of the equivalent sphere of the fungal element passing through the optical bench. This corresponds to the effective hyphal length parameter, or length of the longest hyphae (Nielsen and Krabben 1995), estimated via image analysis (Supplementary Information).

It can be seen from Figure 2, that the PSD is not normally distributed; therefore, the $90^{\text {th }}$

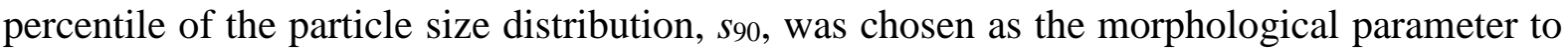
account for the changes in size in the high shear mixer. The $S_{90}$ has been shown to correlate well with rheological properties of fermentation broths (unpublished data), in a manner similar to other morphological parameters (e.g., maximum projected area and the mean maximum dimension) (Riley et al., 2000). In contrast, our previous work shows the $50^{\text {th }}$ percentile of the particle size distribution is a poor rheology-correlating parameter (unpublished data). Figure 3a shows the $S_{90}$ for the PSD illustrated in Figure 2 as a function of time exposed to the high shear mixer along with the $s_{90}$ for the other two replicated measurements of $k_{\text {frag }}$ at each fermentation sample point. For the sample removed at $15 \mathrm{~h}$, the average of three $s_{90}$ measurements at 0 s (i.e., before mixing), is approximately $1270 \mu \mathrm{m}$. This value then decreases over time in the mixer, until it reaches approximately $300 \mu \mathrm{m}$. The sample removed at $52 \mathrm{~h}$ has a different fragmentation pattern; at $0 \mathrm{~s}$ the average of three $s_{90}$ measurements is $1190 \mu \mathrm{m}$, and decreases in size until it reaches $380 \mu \mathrm{m}$ at $55 \mathrm{~s}$. 
To describe hyphal fragmentation, we use our previously published approach (Li et al 2002b). We begin with a model derived from isotropic turbulence theory, originally proposed by van Suijdam and Metz (1981) and used by others (Krabben et al. 1997, Nielsen and Krabben 1995). We combine this model with measurements of average projected area to arrive at:

$$
\frac{d A}{d t}=-k_{f r a g}\left(A^{2}-A_{e q}{ }^{2}\right)
$$

where $A$ is the average projected area for all fungal elements $\left(\mu \mathrm{m}^{-2}\right), t$ is time spent in the high-shear mixer, $k_{\text {frag }}$ is the second order fragmentation rate constant $\left(\mu \mathrm{m}^{-2} \mathrm{~s}^{-1}\right)$, and $A_{\mathrm{eq}}$ is the equilibrium projected area $\left(\mu \mathrm{m}^{-2}\right)$, or the size of the smallest fungal elements (Justen et al. 1998, van Suijdam and Metz 1981). According to Li et al (2002b), initial tests showed $A_{\text {eq }}$ to be relatively small compared to the initial size of fungal elements such that $A>A_{\text {eq. }}$. Thus, integration of equation 1 leads to:

$$
\left(\frac{1}{A}-\frac{1}{A_{0}}\right)=k_{\text {frag }} t
$$

Where $A_{0}$ is the average projected area at the beginning of a fragmentation test (and is identical to the average projected area of fungal elements in the culture at the time sample was removed). Here, we assume $A$ to be proportional to the effective hyphal length (measured by laser diffraction); therefore, we simply use $s_{90}$ in place of the mean projected area as a measurement of fungal element size. Hence,

$$
\left(\frac{1}{s_{90}}-\frac{1}{s_{90,0}}\right)=k_{\text {frag }} t
$$

Thus the relative fragmentation rate, $k_{\mathrm{frag}}$, is the slope of plotting the left hand side of Eq. (3) versus the time the sample has been blended in the high shear mixer, Figure 3b. The values for each slope, 95\% confidence intervals, and regression coefficients can be found in Table I. 
Assuming $k_{\text {frag }}$ to be inversely proportional to the tensile strength, data in Figure 3 suggest hyphae become slightly stronger in the shake flask over time. While very few measurements are available for comparison, we note this finding is consistent with Li et al (2002a), who show an increase in tensile strength over time for a different fungus (A. oryzae). Similarly, Wardell et al. (2002) show increasing tensile strength over time for filamentous bacteria (Saccharopolyspora erythraea).

To validate our approach, we tested the assumption of proportionality between $A$ and $s_{90}$, by determining $k_{f r a g}$, for the same broth sample, with both traditional image analysis methods and the approach described here (Supplementary Information). We find no significant difference between these two approaches $(P=0.61)$.

Finding a measuring window to estimate a constant specific fragmentation rate

Shake flask cultivations were performed to monitor the development of hyphal tensile strength of A. nidulans A4 during exponential growth in complex media. Results are shown in Figure 4. This allowed us to establish a time window where the $k_{\text {frag }}$ measurements should be performed. Thus, a valid comparison can be conducted when evaluating hyphal strength of different strains which may have different growth curves. Since broth volume is the limiting factor in fragmentation experiments, dry cell weight samples were taken in the early growth phase for some flasks and late growth phase for the others. This ensured having enough broth to fragment mycelia and estimate $k_{f r a g}$ values at several time points.

Figure $4 \mathrm{a}$ shows the biomass concentration as a function of time for three shake flask cultivations run as biological replicates. The exponential phase is from 5 to $11 \mathrm{~h}$, and ceases when biomass concentration reaches approximately $2 \mathrm{~g} / \mathrm{L}$ due to oxygen transfer limitations. Similar growth curves are observed in (Zaho et al., 2005). Figure $4 \mathrm{~b}$ displays the $90^{\text {th }}$ percentile of the particle size distribution, S90, as a function of time for five different shake 
flask fermentations. The morphology parameter $S_{90}$ aligns well for the 5 biological replicates. According to the s90 profiles, the size of the cells increases linearly, i.e. there is no exponential increase in size, which indicates that further increase in biomass in the exponential phase is due to branching. This is indeed the mechanism that allows exponential growth of filamentous microorganisms (Spohr et al., 1998). The relative fragmentation rate is illustrated in Figure 4c; there is significant variation in the $k_{\text {frag }}$ measurements at the early stages of the cultivation. The variation however decreases in the latter portion of the flask culture i.e. 13 h. Early variation is due to unstable laser diffraction measurements due to low biomass concentrations. Thus we recommend performing the $k_{\text {frag }}$ measurements when a biomass concentration of at least $1 \mathrm{~g} / \mathrm{L}$ is achieved. Analysis of variance of $k_{\text {frag }}$ from $13 \mathrm{~h}$ to 19 h shows no significant difference ( $p>0.05)$, with a mean value of $4.51 \mathrm{E}-05 \pm 3.01 \mathrm{E}-06$ $\mu \mathrm{m}^{-1} \mathrm{~s}^{-1}(95 \% \mathrm{CI})$.

\section{Hyphal tensile strength in autophagy conditions}

It has been suggested that rapamycin-induced autophagy boosts the expression levels of aglucosidase B (AgdB) to increase glucose monomers from the $\alpha$-glucan fraction of the cell wall, even in the presence of excess external carbon (David et al., 2006). Furthermore, rapamycin-induced autophagy leads to a reduction in the UDP- $N$-acetylglucosamine pyrophosphorylase (UngA), which is an important enzyme in cell-wall biosynthesis in yeasts (Milewski et al., 2006). Thus the effects of rapamycin-induced autophagy are likely to be the degradation of cell wall components, making the cell wall weaker as a result (Kim et al., 2011). To test this hypothesis, we measured the fragmentation rate constant, $k_{\text {frag, }}$, for a strain of $A$. nidulans (TNO2A3) under rapamycin-induced autophagy with the method described above. 
TNO2A3 was grown in complex media (control conditions) and $k_{\text {frag }}$ was measured at different times between 12 and $25 \mathrm{~h}$ after the start of the cultivation. For the rapamycininduced fermentations, $20 \mathrm{mg} / \mathrm{L}$ of rapamycin was added at $10 \mathrm{~h}$, and $k_{\text {frag }}$ was measured between 14 and $24 \mathrm{~h}$ after the start of the cultivation. Figure 5 shows biomass, s90 and $k_{\text {frag }}$ profiles for control and rapamycin-induced autophagy conditions for four biological replicates. In control conditions, cells grow in exponential phase from 3 to $12 \mathrm{~h}$. A biomass concentration of $1 \mathrm{~g} / \mathrm{L}$ is observed approximately at the end of the exponential growth phase. For rapamycin treated cells, the growth rate is reduced from the point the rapamycin was added (10 h), and the biomass concentration is lower in comparison to control conditions from this point onwards. The $s_{90}$ value in the flask (Figure 5b) increases linearly from 6 to 16 h, and then remains constant with an average size of $706 \pm 32 \mu \mathrm{m}$ (95\% CI). In the autophagy induced experiment, the rapamycin was added at $10 \mathrm{~h}$ and the biomass and s90 eventually increased until achieving a size similar to untreated cells, $736 \mu \mathrm{m}$. The $k_{\text {frag }}$ for the control conditions is 3.6E-05 $\pm 2.8 \mathrm{E}-06 \mu \mathrm{m}^{-1} \mathrm{~s}^{-1}(95 \% \mathrm{CI})$, while the $k_{\text {frag }}$ for the rapamycin treated cells is $6.6 \mathrm{E}-05 \pm 5.4 \mathrm{E}-06 \mu \mathrm{m}^{-1} \mathrm{~s}^{-1}(95 \% \mathrm{CI})$. There is a statistically significant difference ( $p=1.4 \mathrm{E}-10)$. The data suggest rapamycin addition resulted in weaker cell walls, observable

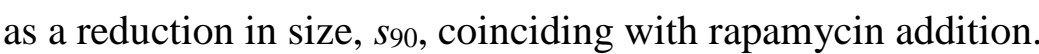

\section{Studying the role of Anatg8 in hyphal strength}

To test the ability of the developed method for assessing the hyphal strength phenotype in response to genetic variations, we measured $k_{\text {frag }}$ for a mutant strain $(\triangle$ Anatg8) lacking a key gene in the autophagy pathway. Cultures of $\triangle$ Anatg8 and its isogenic parent (ie., control strain) were grown in complex media (control) and complex media + rapamycin (autophagy).

Under control conditions, the autophagy deficient mutant strain, $\Delta$ Anatg8, has a very similar growth profile, to the autophagy capable strain (Figure 6a), with maximum growth rates of 
0.40 and $0.37 \mathrm{~h}^{-1}$, respectively, i.e. no significant difference between both strains. However, the lag phase for $\Delta$ atg8 is longer, thus the rapamycin addition was at $13 \mathrm{~h}$ for this strain. It is expected that both strains will have similar growth profiles when grown in complex media since autophagy is largely inactive when adequate nutrients are available (Moss, 2013). For the rapamycin treated cells, the growth rate is reduced after $13 \mathrm{~h}$, Figure $6 \mathrm{a}$.

Figure $6 \mathrm{~b}$ shows the profile for the $90^{\text {th }}$ percentile of the PSD. In general, the s9o increases linearly up to $600 \mu \mathrm{m}$ at $14 \mathrm{~h}$. Then $S_{90}$ increases very slowly up to $20 \mathrm{~h}$ at which point it then begins a slight decrease. The $s_{90}$ for the rapamycin treated cells is similar.

The fragmentation rate for the control conditions for $\Delta$ Anatg8 is 5.8E-05 $\pm 5.8 \mathrm{E}-06 \mu^{-1} \mathrm{~s}^{-1}$. This implies the hyphal tensile strength for the mutant is lower than the paternal strain (TNO2A3), even when autophagy is inactive. There is a statistically significant difference between the $k_{\text {frag }}$ for TNO2A3 under control conditions and the values for $\Delta$ Anatg8 $(\mathrm{p}=7.66$ E-08). These data suggest the Anatg8 protein may play a role outside the autophagy pathway or that the autophagy pathway is required for cell wall strength, even during growth on abundant nutrients. The $k_{\text {frag }}$ value for $\Delta$ Anatg 8 at $18 \mathrm{~h}$ (after rapamycin addition) is significantly higher than the control conditions. However, the effect of rapamycin seems to be transient, as the $k_{\text {frag }}$ values steadily decrease until they align with the control conditions. Although short-lived, the influence of rapamycin causes the autophagy deficient strain to become weaker.

Normalization of the relative fragmentation rate for inter-laboratory comparison

Here, we propose a method to estimate the relative tensile strength of fungal hyphae by measuring the specific rate of fragmentation. We are aware that the rate of fragmentation evaluated in this fashion will depend on the geometry of the high shear mixer, the motor power of that mixer, and potentially other external factors related to the mixer-induced 
fragmentation. Thus, we propose results be reported as the ratio of fragmentation rate for the strain being tested and that for wild type Aspergillus nidulans A4. I.e. the values of $k_{\text {frag }}$ reported in Table II are divided by the $k_{\text {frag }}$ determined for A4, $4.51 \mathrm{E}-05 \mu \mathrm{m}^{-1} \mathrm{~s}^{-1}$, resulting in the normalized $k_{\text {frag }}$ values shown in Figure 7.

While this approach can be used for either process or strain characterization, when we have attempted to use this method to assess strains with deletions of important cell-wall-related genes, results (unpublished) are inconclusive. We find these deletion strains have fragile hyphae, and thus break in the shake flask during growth, leading to much smaller S90,0 values. Thus, when we run the fragmentation assay we see either small differences, or even lower kfrag values, because fragmentation has already occurred in the growth environment. Thus, this assay will be most effective for strains with small or indiscernable size differences during flask culture, as was the case for the strains tested here.

\section{CONCLUSIONS}

In this work, we developed a rapid method to assess a bioprocess-relevant phenotype - the hyphal strength. The developed method allowed us to estimate the fragmentation rate which was assumed to be inversely proportional to the tensile strength. This new tool is inexpensive, fast and simple. The time required to measure each broth sample is approximately 15 minutes, which is a dramatic (approximately 50x) reduction in processing time compared to the previous image analysis method (Li et al., 2002b). This opens the door for future studies

where the impact and changes of genetic manipulations on hyphal strength can be assessed in a quantitative way. This will provide the ability to make rational genetic or environmental changes that will likely impact bioprocess performance. 


\section{REFERENCES}

Amanullah A, Christensen LH, Hansen K, Nienow AW, Thomas CR. 2002. Dependence of morphology on agitation intensity in fed-batch cultures of Aspergillus oryzae and its implications for recombinant protein production. Biotechnol Bioeng 77:815-26.

Bhargava S, Wenger KS, Marten MR. 2003. Pulsed addition of limiting-carbon during Aspergillus oryzae fermentation leads to improved productivity of a recombinant enzyme. Biotechnol Bioeng 82:112-117.

Carlsen M, Spohr AB, Nielsen J, Villadsen J. 1996. Morphology and physiology of an alphaamylase producing strain of Aspergillus oryzae during batch cultivations. Biotechnol Bioeng 49:266-276.

David H, Hofmann G, Oliveira AP, Jarmer H, Nielsen J. 2006. Metabolic network driven snalysis of genome-wide transcription data from Aspergillus nidulans.Genome Biol 7:108.

Harris SD, Morrell JL, Hamer JE. 1994. Identification and characterization of Aspergillus nidulans mutants defective in cytokinesis. Genetics 136:517-532.

Johansen CL, Coolen L, Hunik JH. 1998. Influence of morphology on product formation in Aspergillus awamori during submerged fermentations. Biotechnol Prog 14:233-240.

Justen P, Paul GC, Nienow AW, Thomas CR. 1998. A mathematical model for agitationinduced fragmentation of Penicillium chrysogenum. Bioproc Eng 18:7-16.

Krabben P, Nielsen K, Michelsen ML. 1997. Analysis of single hyphal growth and fragmentation in submerged cultures using a population model. Chem Eng Sci 52:2641-2652. 
Kim Y, Islam N, Moss BJ, Nandakumar MP, Marten MR. 2011. Autophagy induced by rapamycin and carbon-starvation have distinct proteome profiles in Aspergillus nidulans. Biotechnol Bioeng 108:2705-2715.

Li, ZJ, Shukla V, Wenger K, Fordyce A, Pedersen AG, Marten M. 2002a. Estimation of hyphal tensile strength in production-scale Aspergillus oryzae fungal fermentations. Biotechnol Bioeng 77:601-13.

Li, ZJ, Bhargava S, Marten MR. 2002b. Measurements of the fragmentation rate constant imply that the tensile strength of fungal hyphae can change significantly during growth. Biotechnol Lett 24:1-7.

Metz B, Kossen NWF, van Suijdam JC. 1979. The rheology of mould suspensions. Adv Biochem Eng Biotechnol 11:103-156.

Meyer V. 2008. Genetic engineering of filamentous fungi- progress, obstacles and future trends. Biotechnol Adv 26:177-185.

Milewski S, Gabriel I, Olchowy J. 2006. Enzymes of UDP-GlcNAc biosynthesis in yeast. Yeast 23:1-14.

Money N P, Hill TW. 1997. Correlation between endoglucanase secretion and cell wall strength in oomycete hyphae: Implications for growth and morphogenesis.” Mycologia 89:777-785.

Moss B J. 2013. Proteomic analysis of aspergillus nidulans during autophagy and the role of autophagy genes Anatg13 and Anatg8. PhD Thesis, Department of Chemical and Biochemical Engineering. University of Maryland Baltimore County 
Nielsen J, Krabben P. 1995. Hyphal growth and fragmentation of Penicillium chrysogenum in submerged cultures. Biotechnol Bioeng 46:588-598.

Nienow AW. 2009. Scale-up considerations based on studies at the bench scale in stirred bioreactors. J Chem Eng Jpn 42:789-796.

Olsvik E, Kristiansen B. 1994. Rheology of filamentous fermentations. Biotechnol Adv 12:139.

Petersen N, Stocks S, Gernaey KV. 2008. Multivariate models for prediction of rheological characteristics of filamentous fermentation broth from the size distribution. Biotechnol Bioeng 100:61-71.

Pollack J K, Harris SD, Marten MR. 2009. Autophagy in filamentous fungi. Fungal Genet Biol 46:1-8.

Riley GL, Tucker KG, Paul GC, Thomas CR. 2000. Effect of biomass concentration and mycelial morphology on fermentation broth rheology. Biotechnol Bioeng 68:160-172.

Rønnest NP, Stocks SM, Lantz AE, Gernaey KV. 2012. Comparison of laser diffraction and image analysis for measurement of Streptomyces coelicolor cell clumps and pellets. Biotechnol Lett 34:1465-1473.

Spohr A, Agger T, Carlsen M, Nielsen J. 1998. Quantitative morphology of filamentous micro-organisms. In: Wilkinson MHF and Schut F, editors. Digital Image Analysis of Microbes. Wiley \& Sons. p. 373-410.

Stocks SM, Thomas CR. 2001. Strength of mid-logarithmic and stationary åhase Saccharopolyspora erythraea hyphae during a batch fermentation in defined nitrate-mimited medium. Biotechnol Bioeng 73:370-378. 
van Suijdam JC, Metz B. 1981. Influence of engineering variables upon the morphology of filamentous molds. Biotechnol Bioeng 23:111-148.

Warden JN, Stocks SM, Thomas CR, Bushell, ME. 2002. Decreasing the hyphal branching rate of Saccharopolyspora erythraea NRRL 2338 leads to increased resistance to breakage and increased antibiotic production. Biotechnol Bioeng 78:141-146.

Zaho L, Schaefer D, Xu H, Modi SW, LaCourse WR, Marten MR. 2005. Elastic properties of the cell wall of Aspergillus nidulans studied with atomic force microscopy. Biotechnol Prog $21: 292-299$.

Zustiak M P, Pollack JK, Marten MR, Betenbaugh MJ. 2008. Feast or famine: autophagy control and engineering in eukaryotic cell culture. Curr Opin Biotechnol 19:518-526. 


\section{TABLES}

Table I. Fragmentation rate $\left(k_{\mathrm{frag}}\right)$, confidence intervals $(\mathrm{CI})$ and regression coefficient $\left(\mathrm{R}^{2}\right)$ for the slopes shown in Figure 3b. Samples were taken from a shake flask with A. nidulans A4 with complex media at two different time points (15 and 52 h) and the $k_{\text {frag }}$ was determined in triplicates.

$\begin{array}{lllll}\text { Ferm. Time (h) } & \text { Replication } & \mathbf{k}_{\text {frag }}\left({\left.\mu \mathrm{m}^{-1} \mathrm{~s}^{-1}\right)}_{\mathrm{95}} \mathbf{C I}\right. & \mathbf{R}^{2}\end{array}$

\begin{tabular}{|lllll}
\hline 15 & Rep1 & $4.5 \mathrm{E}-05$ & {$[4.21 \mathrm{E}-05,4.78 \mathrm{E}-05]$} & 0.99 \\
& Rep2 & $5.2 \mathrm{E}-05$ & {$[4.89 \mathrm{E}-05,5.50 \mathrm{E}-05]$} & 0.99 \\
& Rep3 & $4.8 \mathrm{E}-05$ & {$[4.33 \mathrm{E}-05,5.30 \mathrm{E}-05]$} & 0.98 \\
& Rep1 & $3.3 \mathrm{E}-05$ & {$[2.78 \mathrm{E}-05,3.82 \mathrm{E}-05]$} & 0.95 \\
& Rep2 & $3.2 \mathrm{E}-05$ & {$[2.97 \mathrm{E}-05,3.43 \mathrm{E}-05]$} & 0.99 \\
& Rep3 & $3.4 \mathrm{E}-05$ & {$[3.09 \mathrm{E}-05,3.71 \mathrm{E}-05]$} & 0.98 \\
\hline
\end{tabular}

This article is protected by copyright. All rights reserved 
Table II. Summary of hyphal fragmentation results for two strains of $A$. nidulans (TNO2A3 and $\Delta$ atg8) under control conditions and rapamycin-induced autophagy.

\begin{tabular}{|c|c|c|c|c|}
\hline Strain & Rap (mg/L) & $\begin{array}{c}\text { kfrag } x \underset{\left.\mathrm{s}^{-1}\right)}{10^{\wedge}-5}\left(\mu \mathrm{m}^{-1}\right. \\
\end{array}$ & $\begin{array}{c}\text { CI }(95 \% \\
\text { confidence) }\end{array}$ & $\mathbf{n}$ \\
\hline TNO2A3 & 0 & 3.64 & 0.28 & 14 \\
\hline$\Delta \operatorname{atg} 8$ & 0 & 5.81 & 0.58 & 12 \\
\hline TNO2A3 & 20 & 6.62 & 0.56 & 13 \\
\hline$\Delta \operatorname{atg} 8$ & 20 & 8.12 & 0.79 & 15 \\
\hline
\end{tabular}

This article is protected by copyright. All rights reserved 


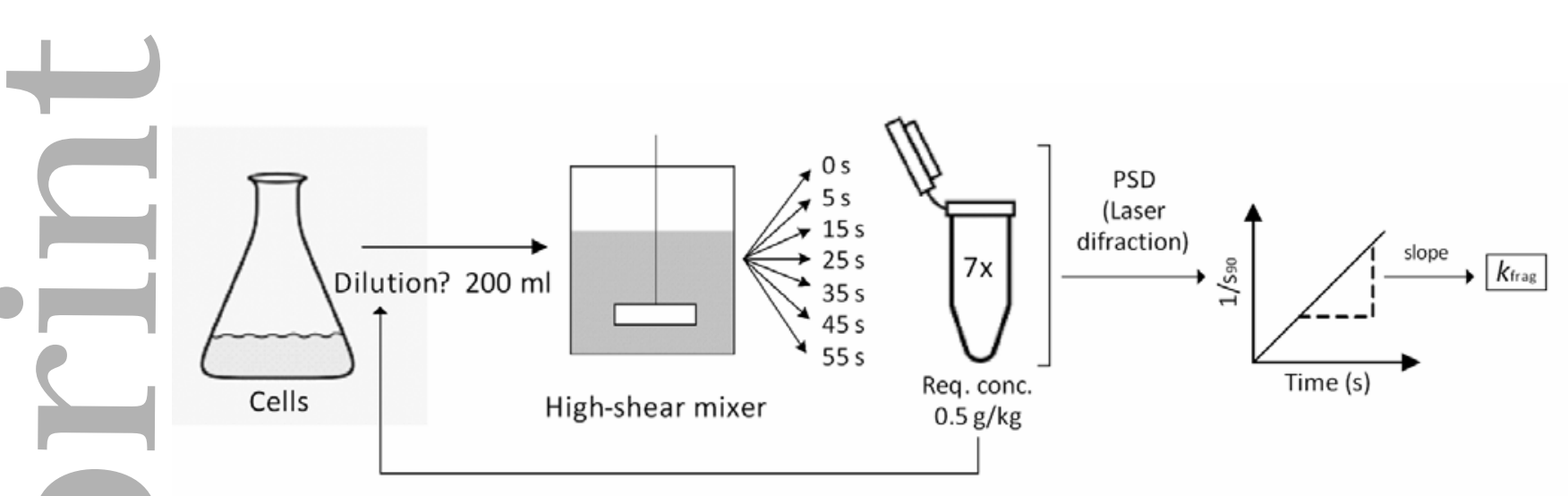

Figure 1. Schematic representation of the protocol to determine the relative hyphal tensile strength. 

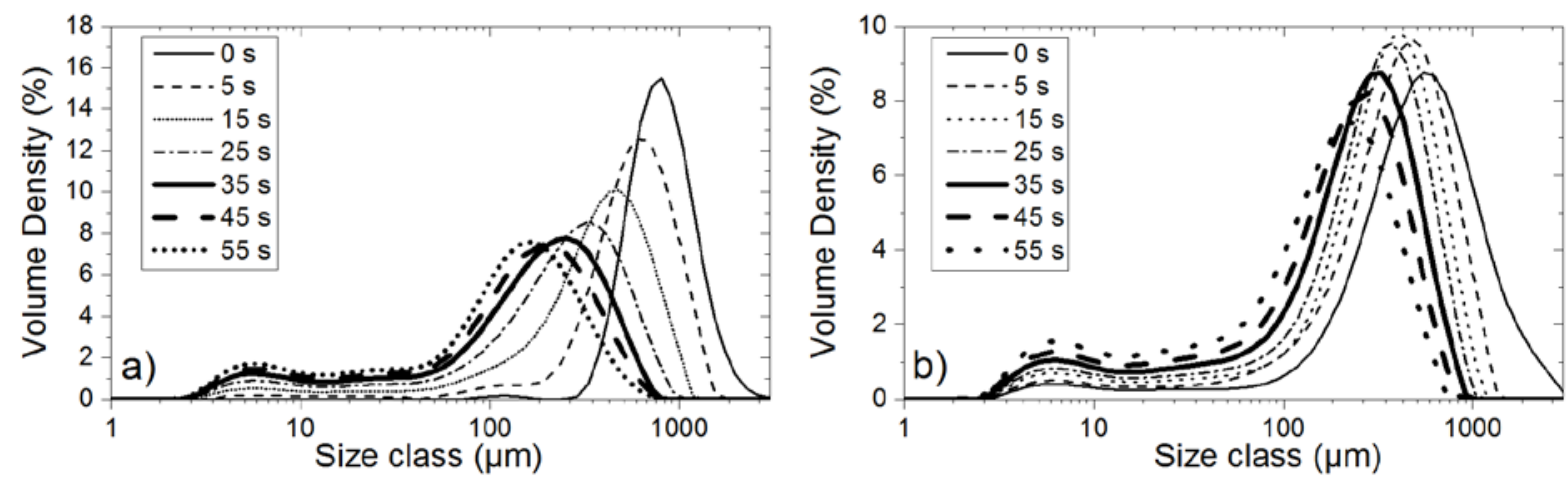

Figure 2. Particle size distributions of $A$. nidulans A4 samples taken from the high shear mixer at short time intervals, i.e. 0 s, 5 s, 15 s, 25 s, 35 s, 45 s and 55 s. a) PSD from a broth sample removed from the shake flasks after $15 \mathrm{~h}$ growth. b) PSD from a broth sample removed from the shake flask after $52 \mathrm{~h}$ growth. 


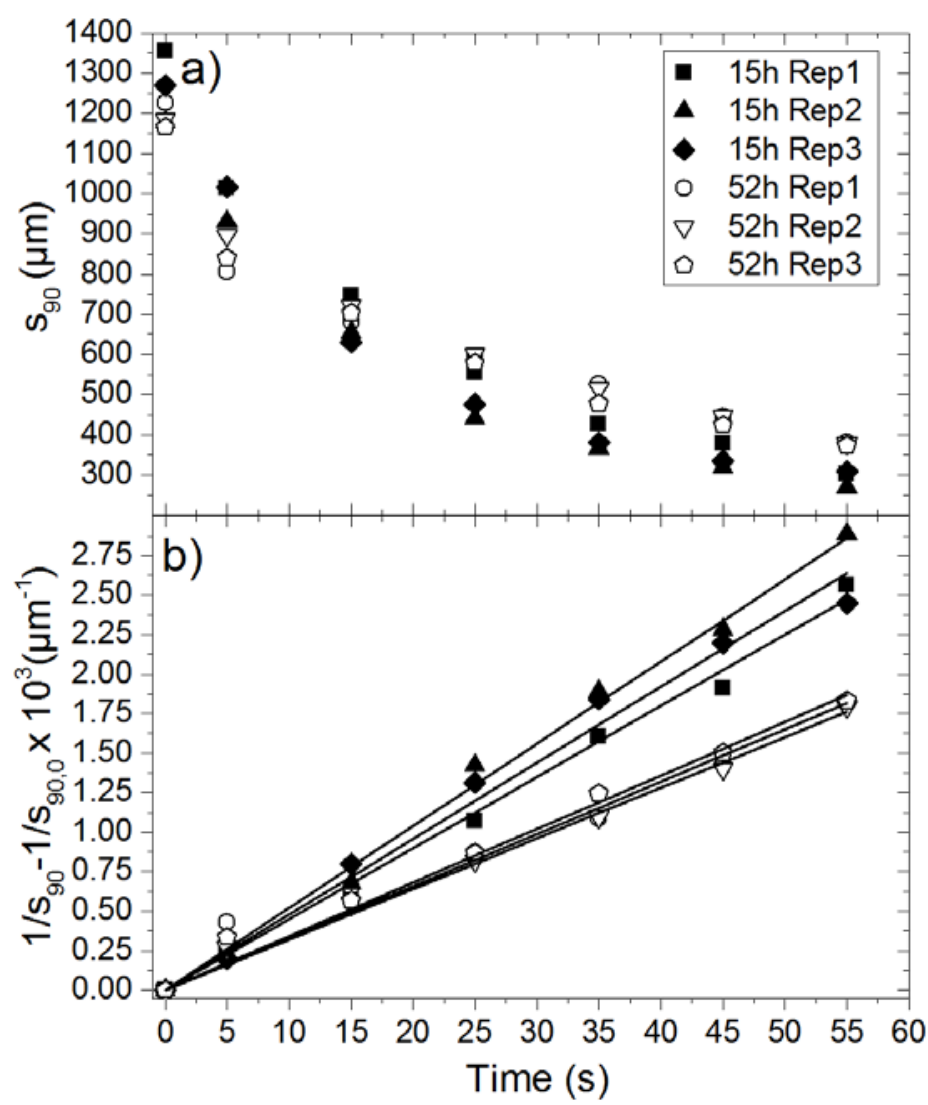

Figure 3. Preliminary results from the fragmentations test performed in A. nidulans A4 grown in complex media, samples taken at different fermentations times: $15 \mathrm{~h}(\boldsymbol{\square}, \boldsymbol{\Delta}, \diamond)$ and $52 \mathrm{~h}(\circ, \nabla, \triangleleft)$. a) Evolution of the $90^{\text {th }}$ percentile of the PSD in the high shear mixer. b) Results after the normalization with Equation. (1). the slope of the curves corresponds to the relative fragmentation rate, $k_{\text {frag. }}$. 


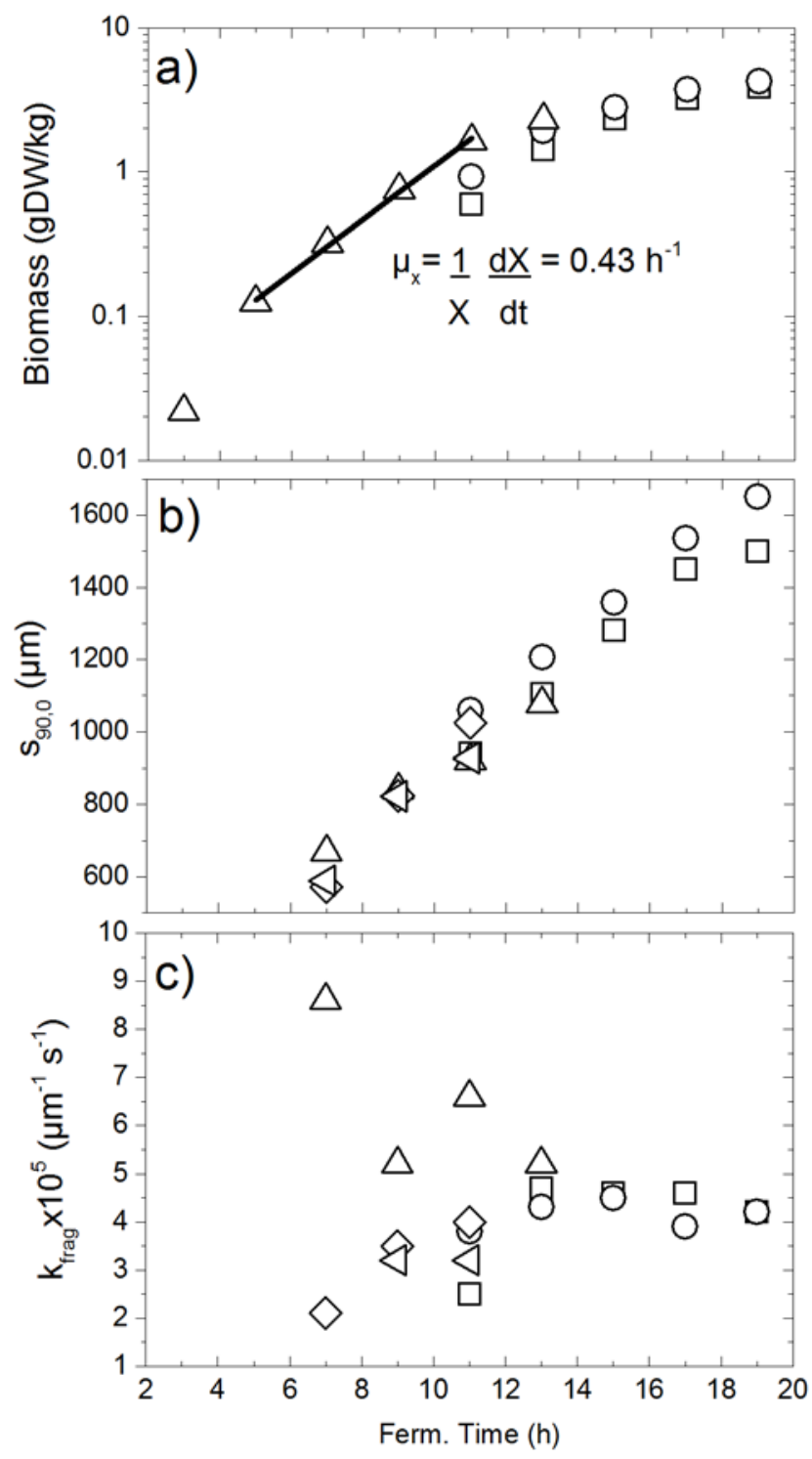

Figure 4. Profiles for $A$. nidulans A4 shake-flask fermentation with complex medium. a) biomass concentration (dry cell weight), b) $90^{\text {th }}$ percentile of the particle size distribution as indication of morphology and c) fragmentation rate $k_{\text {frag }}$. The different symbols represent biological replicates. 

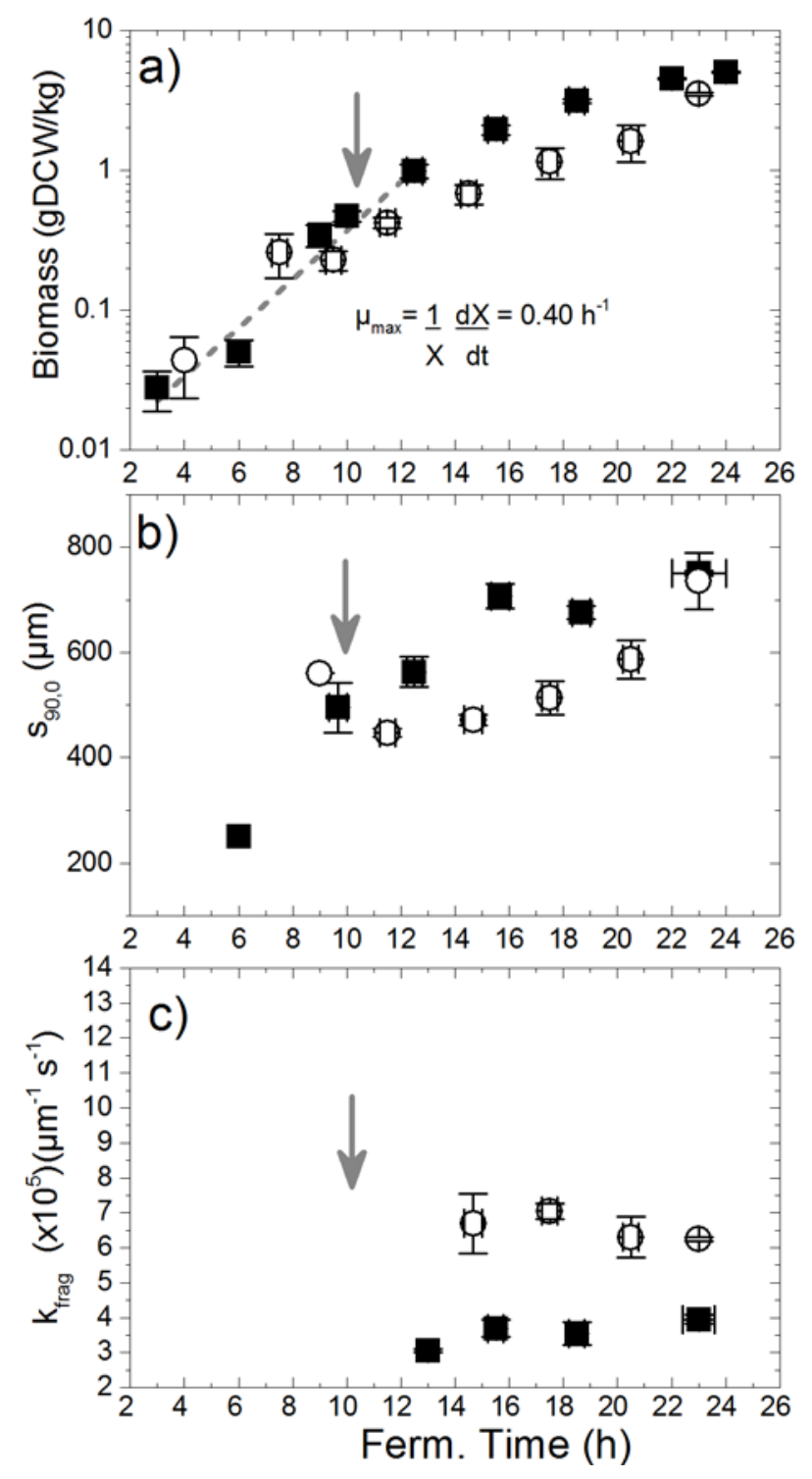

Figure 5. Results from $A$. nidulans TNO2A3 shake flasks cultivations with complex media at control conditions ( $\boldsymbol{a})$ and with autophagy induction by rapamycin addition ( $($ ). a) Biomass concentration (dry cell weight), b) $90^{\text {th }}$ percentile of the PSD (morphological parameter) c)

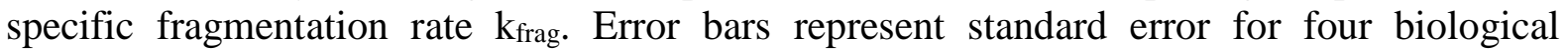
replicates. The gray arrow indicates the rapamycin addition. 

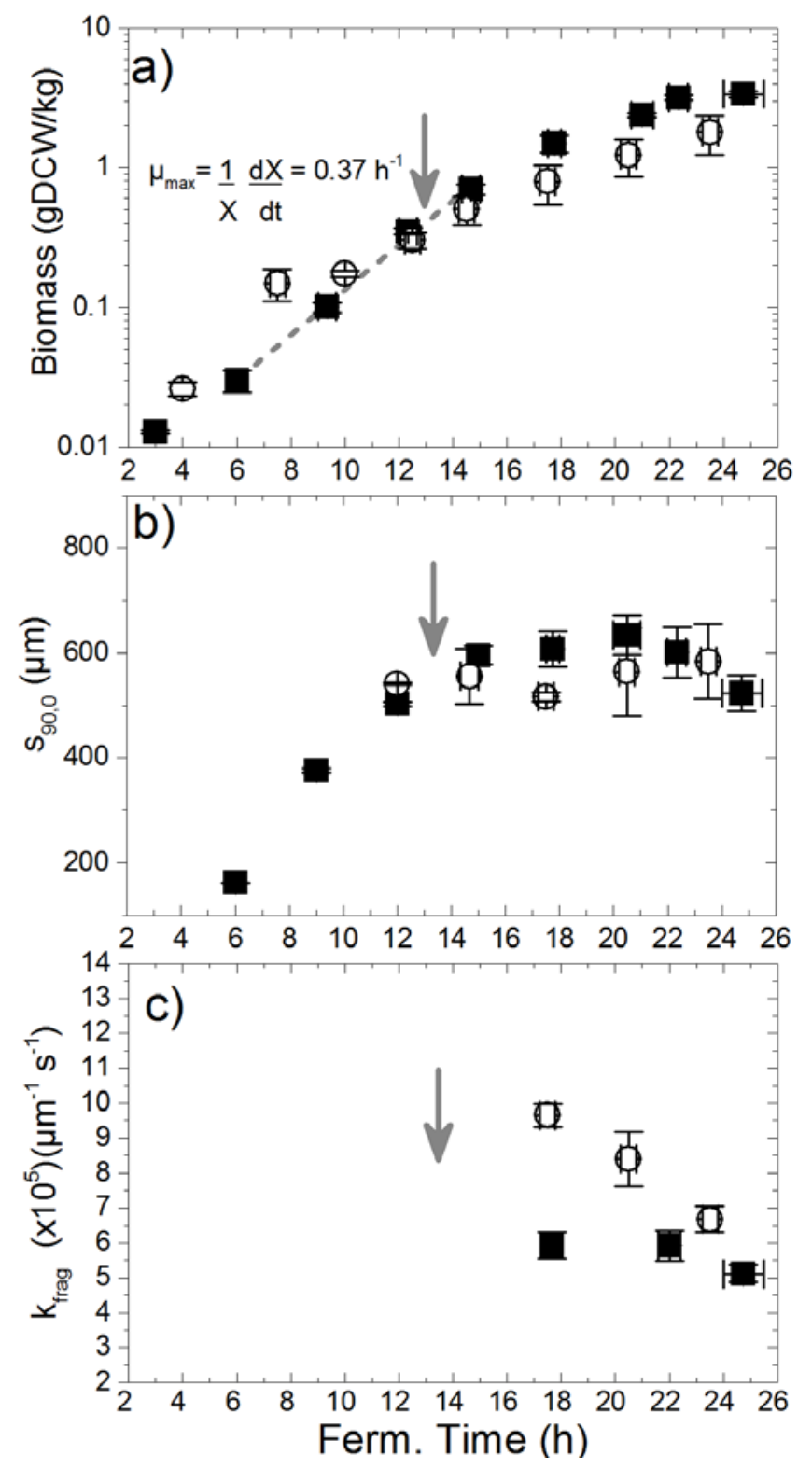

Figure 6. Results from $A$. nidulans $\Delta$ atg8 shake flasks cultivations with complex media at control conditions ( $\mathbf{\square})$ and with autophagy induction by rapamycin addition (O). a) Biomass concentration (dry cell weight); b) $90^{\text {th }}$ percentile of the PSD (morphological parameter); c) specific fragmentation rate $\mathrm{k}_{\text {frag. }}$. Error bars represent standard error for four biological replicates. The gray arrow indicates the rapamycin addition. 


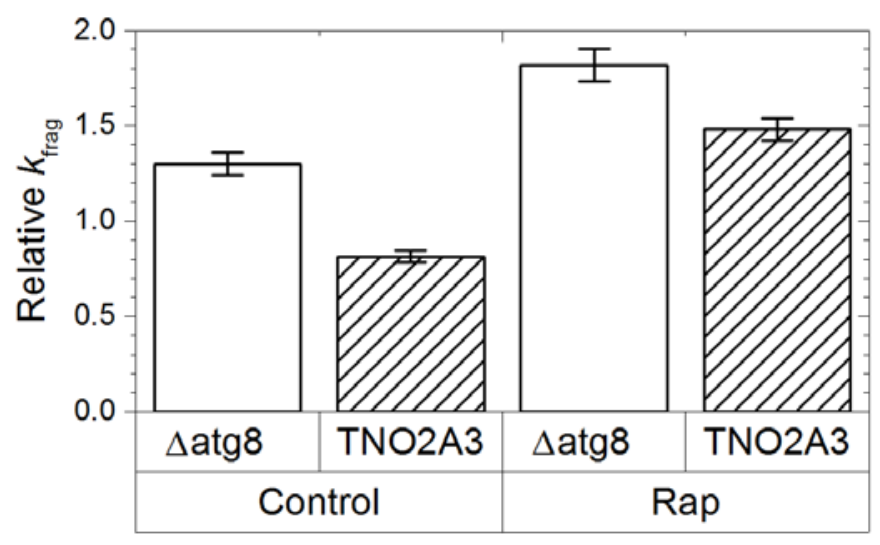

Figure 7. Normalized hyphal fragmentation rate for two strains of $A$. nidulans ( $\Delta$ atg8 and TNO2A3) at control and rapamycin induced conditions. Error bars represent the standard error divided by the average $k_{\text {frag }}$ for A4. 